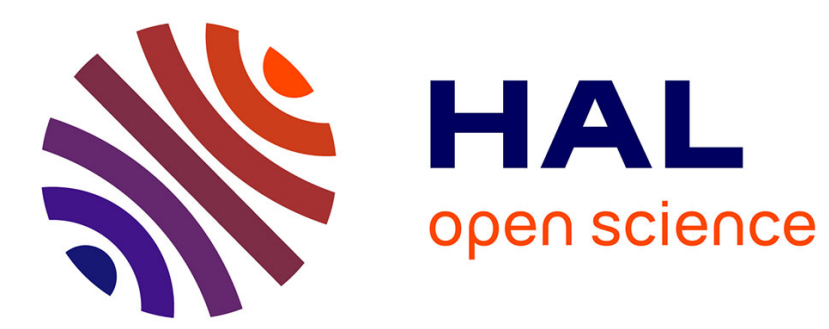

\title{
Online Dispute Resolution and Bargaining
}

Yannick Gabuthy

\section{- To cite this version:}

Yannick Gabuthy. Online Dispute Resolution and Bargaining. 2003. halshs-00178556

\section{HAL Id: halshs-00178556 \\ https://shs.hal.science/halshs-00178556}

Submitted on 11 Oct 2007

HAL is a multi-disciplinary open access archive for the deposit and dissemination of scientific research documents, whether they are published or not. The documents may come from teaching and research institutions in France or abroad, or from public or private research centers.
L'archive ouverte pluridisciplinaire HAL, est destinée au dépôt et à la diffusion de documents scientifiques de niveau recherche, publiés ou non, émanant des établissements d'enseignement et de recherche français ou étrangers, des laboratoires publics ou privés. 
W.P. 03-04

\title{
Online Dispute Resolution and Bargaining
}

\author{
Yannick GABUTHY
}

Mai 2003

GATE Groupe d'Analyse et de Théorie Économique UMR 5824 du CNRS

93 chemin des Mouilles - 69130 Écully - France

B.P. $167-69131$ Écully Cedex

Tél. +33 (0)4 72866060 - Fax +33 (0)4 72866090

Messagerie électronique gate@gate.cnrs.fr

Serveur Web : www.gate.cnrs.fr 
Yannick Gabuthy

GATE,

gabuthy@gate.cnrs.fr

\title{
Online Dispute Resolution and Bargaining ${ }^{1}$
}

\begin{abstract}
Automated negotiation process seems to be a powerful mechanism to resolve disputes arising from Internet-based transactions. Automated negotiation is an online blind-bidding process in which an automated algorithm evaluates bids from the parties and settles the case if the offers are within a prescribed range. $\backslash$ Following the arguments of the dispute resolution professionals, the main advantage of this procedure is to promote "natural" agreements by restoring the parties' right to negotiate on their own, without the presence of a third party in the shadow of negotiations. Our purpose is to investigate this issue by modelling the automated negotiation process as a two-person bargaining game under incomplete information. A first result states that, given incomplete information, not all mutually beneficial agreements can be attained via the procedure. Furthermore, the settlement rule has a drastic effect on the players' strategies, which induce that the automated negotiation process does not significantly increase the likelihood of a settlement. The ability of the procedure to generate efficiency is only due to the costs imposed on parties if a disagreement occurs, that is the combination of players' risk aversion and uncertainty.
\end{abstract}

Keywords: Online Dispute Resolution, Arbitration, Double Auction, Bargaining, Incomplete Information.

JEL Classification: K41, C78, D80.

\section{"A global alternative dispute resolution system is necessary to encourage cross-border electronic commerce".}

Carly Fiorina, CEO, Hewlett-Packard - Meeting of the Global Business Dialogue on eCommerce, September 26, 2000, Florida.

\section{Résolution des conflits en ligne et négociation}

Résumé: La procédure de négociation automatisée semble être une solution adéquate aux litiges issus du commerce électronique. Cette procédure consiste en un programme informatique de résolution des conflits, accessible en ligne, qui analyse les propositions d'accord émises par les parties et résout le conflit si ces offres appartiennent à un intervalle prédéterminé. Selon la profession juridique, le principal avantage de ce mécanisme réside dans sa capacité à rétablir le droit inhérent des individus à négocier par eux-mêmes, facilitant ainsi l'obtention d'un accord librement consenti, sans l'intervention d'une tierce partie.

\footnotetext{
${ }^{1}$ I thank Bruno Deffains, Laurent Flochel, Nadège Marchand, Abhinay Muthoo, and JeanLouis Rullière for their useful comments.
} 
L'objectif majeur de ce papier est d'analyser l'efficience de cette procédure via sa capacité à promouvoir l'obtention d'un accord. Le cadre théorique utilisé est un modèle de doubleenchère avec information incomplète. Tout d'abord, cette caractéristique informationnelle génère nécessairement un résultat inefficient. De plus, la règle de négociation utilisée a un impact très important sur le comportement de négociation des parties, ce qui implique qu'elle introduit un biais important dans l'issue du conflit et n'accroît pas significativement la probabilité d'obtention d'un accord. Sa capacité à générer un résultat efficient provient uniquement des coûts imposés aux parties en cas de désaccord, liés à leur aversion au risque et à la présence d'incertitude.

Mots-clé: Résolution des conflits en ligne, Arbitrage, Double enchère, Négociation, Information incomplète. 


\section{Introduction}

The emergence of the Internet as a commercial phenomenon has resulted in an explosion of interest in online dispute resolution. Online dispute resolution consists of a variety of methods such as arbitration and automated negotiation that utilizes the Internet as a means to more efficiently engage parties in non-litigious dispute resolution ${ }^{1}$. More specifically, online dispute resolution resolves disputes by harnessing computer-networking technology to bring parties together in a dialogue that is usually hosted by a third party service provider. Typically, the resolution process begins when a claimant registers with an online dispute resolution service provider ${ }^{2}$, such as "Allsettle.com" or "Settlementnow.com". The provider then uses the information provided by the claimant to contact the defendant party and invite them to participate in online dispute resolution. If the other party accepts the invitation, they will then file a response to the claimant's complaint ${ }^{3}$. From this point, the various providers utilize different methodologies. Some have developed proprietary software that allows parties to engage in automated negotiation of monetary sums without the participation of a neutral arbitrator. To fix ideas, the software accepts sealed offers from the parties without the participation of an arbitrator in the shadow of negotiations. Once the parties' offers are within a specified range (in a sense to be defined later) the case settles.

Such online dispute resolution mechanisms have strong policy implications in bridging the gap between the Internet and existing laws, and has not received any attention in economics. With the rapid growth of e-commerce and cross-border transactions, consumers and companies found it increasingly difficult to resolve complaints generated from online transactions. The widespread transboundary transactions are a new phenomenon, and businesses are only starting to wrestle with the challenges presented by them. For instance, suppose that you purchase a product from an auction site. First, it is harder to know if the seller you are working with on the other side of the planet can be trusted. More significant, it is unclear what happens if something goes wrong with the sale (e.g. misrepresentation or non-delivery of the product). What form of jurisdiction is proper for a consumer or business seeking remedy with respect to a problematic Internet-based transaction? How is it possible to haul individuals into court when they may live halfway around the globe? Consumers who participate in this type of commerce expose themselves to a heightened level of risk due to the anonymity and location of the individual making a sale or purchase (Deffains and Fenoglio 2001). Online dispute resolution is then a powerful settlement tool

\footnotetext{
${ }^{1}$ For a survey of these procedures, see the Center of Law, Commerce and Technology - University of Washington School of Law - http://law.washington.edu/lct/.

${ }^{2}$ The provider is simply the website delivering the online dispute resolution process.

${ }^{3}$ Many of the online market sites (e.g. eBay, Amazon) have developed reputation management systems that allow the trading parties to submit a rating of the counter party's performance in a specific transaction, which will be made available to all visitors of the site (Keser 2002). In this context, the defendant party has a strong incentive to accept the provider's invitation.
} 
in which the legal location and anonimity of the parties do not matter, since the resolution is crafted based on the preferences of the parties and does not require the physical presence of them. This is the primary reason for which many organizations have called for a variety of business-to-consumer companies to integrate online dispute resolution into their practices. The Global Business Dialogue on e-Commerce (which includes AOL Time Warner, Hewlett-Packard, and DaimlerChrysler), the Electronic Commerce and Consumer Protection Group (including Dell, Microsoft, and Visa), and the International Chamber of Commerce have all issued recommandations that e-commerce companies make online dispute resolution available to their customers to resolve any disputes that arise. Online dispute resolution is applicable in a wide variety of areas, however, the first e-commerce environment to make use of automated negotiation was auction sites. As explained above, these sites are particularly vulnerable to conflict because it is difficult to find out who is on the other side of the transaction ${ }^{4}$. In March 2000, the online dispute resolution provider "Squaretrade.com" has been integrated into the online auction eBay in order to reassure buyers and sellers. However, because many cases come down to a monetary amount, the insurance industry is by far the largest user of automated negotiation mechanism. Indeed, the largest online dispute resolution mechanisms that have emerged so far, such as "Allsettle.com" and "Cybersettle.com", have focused primarly on this market. Once an accident occurs the insurance companies deal first with the involved parties and then with each other ${ }^{5}$. The negotiations between insurance companies to resolve differences over payment obligations is a complex and costly process, which can be largely helped by online dispute resolution.

Comparing to traditional arbitration, many dispute resolution professionals argue that the main advantage of automated negotiation is to restore and promote the parties' right to negotiate on their own, without the presence of a third party in the shadow of negotiations. Following the arguments by Crawford (1979), Farber and Katz (1979), and Farber (1981), arbitration will lead the parties' offers to converge to the arbitrator's settlement, as one party can always improve on any offer by offering the arbitrator's preferred settlement. Of course, given positive arbitration costs, arbitration should actually not be used at all. This apparent success of arbitration indicates only that bargainers, while appearing to negotiate their own settlements, have correctly perceived the arbitrator's wishes and yielded to conform to them. In this case, the parties are simply agreeing on what the arbitrator would award anyway, so arbitration is actually the determining factor, not negotiation:

"... Bargaining is any process through which the players on their own try to reach an

\footnotetext{
${ }^{4}$ For example, the number of online auction complaints received by the United States Federal Trade Commission shot up from 107 in 1997 to 10.700 in 1999.

${ }^{5}$ The two main divisions of consumer-focused insurance companies are the property-casualty insurers, which deal with policies like auto or home assurance, and life-health insurers, which deal with medical and life insurance.
} 
agreement... If the players get a third party to help them determine the agreement, then this means that agreement is not reached via bargaining." 6

The use of an automated negotiation mechanism as a dispute resolution procedure seems to be able to promote a more "natural" convergence by transferring the decision-making authority to the parties (instead of the arbitrator), who keep then the control of the bargaining process and its outcome.

Our principal aim is to investigate this issue by modelling the automated negotiation procedure as a two-person bargaining under incomplete information. Like Chatterjee and Samuelson (1983), we frame the bargaining situation as a double auction game and focus on the resulting set of equilibrium outcomes. Let us briefly elaborate. Acting independently and without prior communication, seller and buyer submit price offers $p_{s}$ and $p_{b}$ respectively. If these offers are compatible, a transaction is concluded at a price that depends on the offers; if they are not, then no transaction takes place. However, the design of the automated negociation mechanism differs from the traditional double auction approach on the compatibility criterium. Chatterjee and Samuelson (1983) consider that the offers are compatible if and only if the price offered by the buyer is higher than the price proposed by the seller (i.e. $p_{b} \geq p_{s}$ ), while we assume, following the automated negotiation process explained above, that the offers are compatible if they are just within a specified range (i.e. $p_{b}(1+\delta) \geq p_{s}$ even if $p_{b}<p_{s}$, where $\delta \in[0,1)$ will be called the compatibility factor $\left.^{7}\right)$. Therefore, it seems that the automated negotiation procedure would be able to help the disputants to reach an agreement, where the degree to which it can do so is captured by the magnitude of the parameter $\delta$. A first result is that, given incomplete information, not all mutually beneficial agreements can be attained via the procedure. Even when the buyer values the good more highly than the seller, a successful sale may be impossible. Additionaly, we present useful comparative statics results indicating the effect on the probability that a settlement occurs of changes in the parameter $\delta$ and the degree of players' risk aversion. It appears that the parameter $\delta$ is an important factor determining the players' offer strategies. As $\delta$ increases, the disputants are motivated to make more aggressive offers which induce that the automated negotiation procedure does not significantly increase the range of possible settlements. Surprisingly, this result suggests that automated negotiation design is not a good way for increasing the likelihood of a settlement, in the sense that it creates a prisonner's dilemma situation: each party has a strong individual incentive to exploit strategically the compatibility factor and adopt aggressive positions, which leads to a collective inefficient result. The ability of the procedure to generate efficiency is only due to the costs imposed on parties if a disagreement occurs, that is the combination of players' risk aversion and uncertainty regarding the opponent's reservation price.

\footnotetext{
${ }^{6}$ Abhinay Muthoo (1999), p.2.

${ }^{7}$ Following the existing automated negotiation procedures, we consider that the compatibility factor is common knowledge.
} 
The remainder of the paper is organized as follows. Section 2 lays down our model, and derives our main results concerning the equilibrium strategies and how they depend on the compatibility factor. The equilibrium implications of the players' risk aversion is also discussed in this section. Section 3 concludes by describing a possible extension of the model.

\section{The Model}

\subsection{Strategic Environment}

Framework. We consider two players, a buyer and a seller of an indivisible good, $N=$ $\{b, s\}$. A settlement is concluded if and only if the good is transferred at an acceptable price. Let $v_{s}$ denote the seller's reservation price (i.e. the smallest monetary sum he will accept in exchange for the good). Similarly, let $v_{b}$ denote the buyer's reservation price (i.e. the greatest sum he is willing to pay for the good $)^{8}$. The valuations of the good of the buyer and the seller are their private information. Incomplete information of the bargainers is modeled by the following assumption: each party knows his own reservation price, but his uncertain about his adversary's, assessing a subjective probability distribution over the range of possible values that his opponent might hold. Specifically, each party regards the opponent's reservation value as a random variable drawn from an independent uniform distribution, and these distribution functions are common knowledge. Each bargainer $i$ is likely to have a reservation value $v_{i}$ between 0 and 1 , and every value of $v_{i}$ in that interval has the same chance of occurring. Therefore, the type spaces are respectively $T_{b}=\left\{0 \leq v_{b} \leq 1\right\}$ and $T_{s}=\left\{0 \leq v_{s} \leq 1\right\}$. The incomplete information approach provides a useful framework to take into account some key features of actual negotiations: the fact that each bargainer is uncertain about its adversary's payoff and the possible occurence of "unreasonable" bargaining outcomes, such as breakdowns in negotiations, even when mutually beneficial agreements are possible. In this framework, bargaining behavior depends on a player's reservation price, his assessment of the opponent's reservation price, the knowledge of the opponent's assessment, and the compatibility factor between the players' offers assumed by the automated negotiation process. This procedure provides the following bargaining structure.

Bargaining rule. Buyer and seller submit simultaneous offers, $p_{b}$ and $p_{s}$ respectively, defining the action spaces $A_{b}=\left\{p_{b} \geq 0\right\}$ and $A_{s}=\left\{p_{s} \geq 0\right\}$. The computer software analyzes the offers to see if a settlement has been reached. If the offers converge or crisscross (i.e. $p_{b} \geq p_{s}$ ), then the case is settled and the good is sold at price $p=p_{s}$. If they are not, but differ by less than $\delta$ (i.e. $\left.p_{b}(1+\delta) \geq p_{s}>p_{b}\right)$, then the case is also settled

\footnotetext{
${ }^{8}$ Even though we keep the terminology used by Chatterjee and Samuelson (1983), it may be helpful to think of the seller as a plaintiff and the buyer as a defendant who bargain over the price at which the plaintiff will sell his claim to the lawsuit.
} 
and the good is sold at price $p=\left(p_{b}+p_{s}\right) / 2$, where $\delta \in[0,1)$ is the compatibility factor associated to the automated negotiation procedure. In this latter case, the rule determines the settlement price by splitting the difference between the players' offers. If the offers differ by more than $\delta$, then the agreement is not reached. In this case, there is no sale and no money trades hands since each player's payoff from disagreement is zero. In order to illustrate conveniently the bargaining rule of the automated negotiation mechanism, let us take an example. We suppose that $\delta=30 \%$ and consider the three cases mentioned above:

\begin{tabular}{|c||c|c|c|c|}
\hline Case & Buyer's offer $\left(p_{b}\right)$ & Seller's demand $\left(p_{s}\right)$ & Result & Detail \\
\hline \hline 1 & $\$ 35,000$ & $\$ 30,000$ & Settlement for $\$ 30,000$ & $\begin{array}{c}p_{b}>p_{s} \\
\rightarrow p=p_{s}\end{array}$ \\
\hline 2 & $\$ 30,000$ & $\$ 38,000$ & Settlement for $\$ 34,000$ & $\begin{array}{c}p_{b}(1+\delta) \geq p_{s}>p_{b} \\
\rightarrow p=\left(p_{b}+p_{s}\right) / 2\end{array}$ \\
\hline 3 & $\$ 20,000$ & $\$ 60,000$ & No Settlement & $\begin{array}{c}p_{b}(1+\delta)<p_{s} \\
\rightarrow \text { No agreement }\end{array}$ \\
\hline
\end{tabular}

A main focus of attention concerns the role and impact that $\delta$ may have on the bargaining behavior and the likelihood of a settlement, given that the actual automated negotiation procedures consider different values of $\delta$. For example, "123Settle.com" consider that the case is settled if the offers are within a range of $\delta=20 \%$, while "clickNsettle.com" and "Settlementnow.com" provide a compatibility factor of $\delta=30 \%$. In order to conduct our analysis in a simplified manner and isolate this potential role of the compatibility factor, we deliberately omit from our model various other elements of automated negotiation procedures that would also have some role and impact on the issue under study. Especially, some restrictive assumptions are made in order to develop understanding and intuition about the role of the forces under study in a sharper manner.

Assumptions. First, we substitute a single stage bargaining procedure for the multistage representation usually considered in the automated negotiation procedures, in which the buyer and the seller are involved in a finite sequence of the one-shot game described above. For example, "Allsettle.com" and "Settlesmart.com" provide three periods to the parties for reaching an agreement. Through abstracting from the dynamics of the negotiation process, the single stage bargaining procedure emphasizes the basic strategy trade-off faced by each player. By making a more aggressive offer, a player earns a greater profit in the event of an agreement but, at the same time, increases the risk of a disagreement, depending on the value of the compatibility factor.

Second, we assume, without lost of generality, that there is no direct cost for the parties from using the automated negotiation service - this is a simplifying modelling assumption. Currently the automated negotiation providers use a wide range of fee structures, although the fees are less expensive than traditional litigation. There is no one fee structure that 
appears to be dominant, however, it is common for companies to employ a submission fee (incurred by the party requesting the resolution) and a settlement fee (incurred by both parties if and only if a successful settlement is reached).

Finally, we implicitly assume throughout this paper that the agreement struck via the automated negotiation process is binding for the parties. Indeed, the actual users of such services have to agree in writing to be legally bound by all settlements arising from the negotiation. Therefore, settlements are binding on both parties and preclude them from seeking redress in court for the same claim. In addition, parties are barred from bringing any other suit arising from the same facts from which the claim arose.

Framing the single stage bargain as a noncooperative game, we will characterize the resulting Bayesian Nash equilibria. In the event of an agreement, each player earns a profit measured by the difference between the agreed price and his reservation price $\left(p-v_{s}\right.$ for the seller and $v_{b}-p$ for the buyer); in the event of no agreement, each earns a zero profit. The payoffs to both the buyer and the seller are then:

$$
\begin{aligned}
& u_{b}\left(p_{s}, p_{b} ; v_{s}, v_{b}\right)= \begin{cases}v_{b}-p_{s} & \text { if } p_{b} \geq p_{s} \\
v_{b}-\frac{p_{b}+p_{s}}{2} & \text { if } p_{b}(1+\delta) \geq p_{s}>p_{b} \\
0 & \text { if } p_{b}(1+\delta)<p_{s}\end{cases} \\
& u_{s}\left(p_{s}, p_{b} ; v_{s}, v_{b}\right)= \begin{cases}p_{s}-v_{s} & \text { if } p_{b} \geq p_{s} \\
\frac{p_{b}+p_{s}}{2}-v_{s} & \text { if } p_{b}(1+\delta) \geq p_{s}>p_{b} \\
0 & \text { if } p_{b}(1+\delta)<p_{s}\end{cases}
\end{aligned}
$$

Additionally, we assume that each bargainer makes offers to maximize his expected profit and we restrict attention to striclty monotonic and differentiable strategies for the two players. In this static bayesian game, a strategy for the buyer is a function $p_{b}\left(v_{b}\right)$ and a strategy for the seller is a function $p_{s}\left(v_{s}\right)$, indicating that the players' price offers depend on their respective reservation prices.

Consider now the buyer's best reply. This is defined by the following maximization problem:

$$
\max _{p_{b}} E_{v_{s}}\left\{u_{b}\left(p_{s}, p_{b} ; v_{s}, v_{b}\right) / v_{b}, p_{s}\left(v_{s}\right)\right\}
$$

The seller's best reply is defined by the following maximization problem:

$$
\max _{p_{s}} E_{v_{b}}\left\{u_{s}\left(p_{s}, p_{b} ; v_{s}, v_{b}\right) / v_{s}, p_{b}\left(v_{b}\right)\right\}
$$

Then player $i$ employs a best response strategy if for each $v_{i}$ his offer is a best response against his opponent's strategy. A pair of best response offer strategies constitute a Bayesian Nash equilibrium. 


\subsection{Equilibrium strategies and Settlement}

Benchmark case. As a benchmark, we consider first the case where there is no compatibility factor (i.e. $\delta=0$ ). This example is useful to derive some comparative statics results indicating the effect on bargaining behavior of changes in the value of $\delta$. In that case the payoffs to both the buyer and the seller become:

$$
\begin{aligned}
& u_{b}\left(p_{s}, p_{b} ; v_{s}, v_{b}\right)= \begin{cases}v_{b}-p_{s} & \text { if } p_{b} \geq p_{s} \\
0 & \text { if } p_{b}<p_{s}\end{cases} \\
& u_{s}\left(p_{s}, p_{b} ; v_{s}, v_{b}\right)= \begin{cases}p_{s}-v_{s} & \text { if } p_{b} \geq p_{s} \\
0 & \text { if } p_{b}<p_{s}\end{cases}
\end{aligned}
$$

A fundamental property of equilibrium offer strategies for which agreements occur is that they are increasing in the individual reservation prices. The higher the value placed on the good by the seller (resp. buyer), the higher the price he demands (resp. offers).

Lemma 1. Under the automated negotiation bargaining rule, considering the case in which there is no compatibility factor, the equilibrium offer strategies are

$$
p_{b}\left(v_{b}\right)=v_{b} \text { and } p_{s}\left(v_{s}\right)=\frac{1}{2} v_{s}+\frac{1}{2}
$$

Proof. See appendix 4.1.

In other words the buyer's offer coincides with his reservation price while the seller's asking price is biased upward with respect to his valuation. The intuition behind this result is the following. When a settlement is reached, the good is sold at price $p=p_{s}$, therefore the rule is equivalent to granting the seller the right to make a first and final offer that the buyer can accept or reject. In this instance, the sale price is determined solely by the seller's offer, while the buyer's offer serves only to determine whether there is an agreement or not. The buyer's optimal strategy is then to make a truthful offer (i.e. $p_{b}=v_{b}$ for all $v_{b}$ ). Furthermore, given that an agreement is reached if and only if $p_{b} \geq p_{s}$, manipulating the equilibrium offer strategies in Lemma 1 shows that an agreement occurs in the equilibrium if and only if:

$$
v_{b} \geq \frac{1}{2} v_{s}+\frac{1}{2}
$$

Comparing with the ex-post efficient trading pattern, we conclude that there is too little trading in equilibrium, as stated in Proposition 1. In terms of Myerson and Satterthwaite (1983)'s analysis we argue that there exists an inefficiency in the bilateral trading model. 
Proposition 1. Under the automated negotiation bargaining rule, considering the case in which there is no compatibility factor, the settlement zone is under-efficient.

This implies that, under this assumption, there is no Bayesian Nash equilibrium of the automated negotiation game in which trade occurs if and only if it is efficient (i.e. if and only if $v_{b} \geq v_{s}$ ). Given incomplete information, not all mutually beneficial agreements can be attained via bargaining and Coase's Theorem fails to apply (Coase 1937). Even when the buyer values the good more highly than the seller, a successful settlement may be impossible. The inefficiency generated by the bilateral trading mechanism is represented by the hatched area on Figure 1:

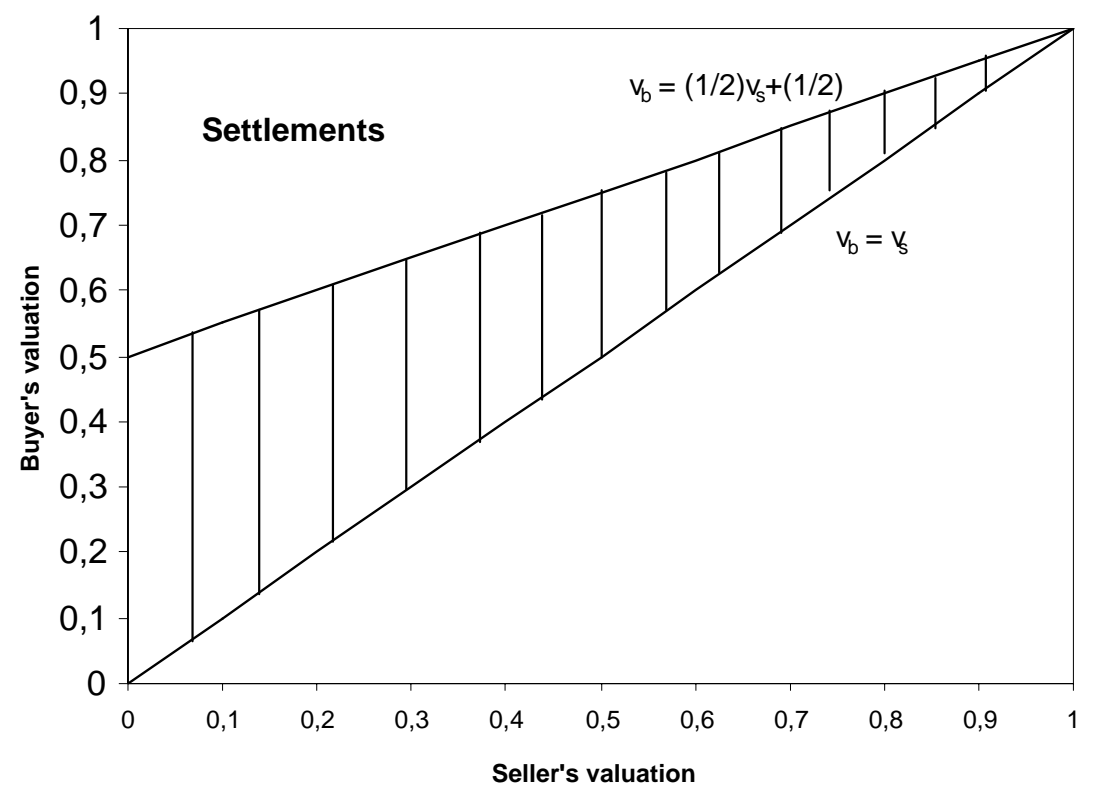

Figure 1 - Settlement zone when $\delta=0$

Compatibility factor. The next analysis characterizes the equilibrium strategies for a positive compatibility factor (i.e. $\delta>0$ ). It would appear at first blush that an increase in the value of $\delta$ improves the efficiency of the automated negotiation procedure by increasing the settlement zone. In the case where $\delta=0$, an agreement occurs only when there is some "bargaining space" between the two offers (i.e. when $p_{b}-p_{s} \geq 0$ ), while a positive $\delta$ provides the parties a possibility to reach an agreement even when this "bargaining space" does not exist (i.e. when $p_{b}-p_{s}<0$, provided that $p_{b}(1+\delta)-p_{s} \geq 0$ ). Therefore, should not a positive compatibility factor signifies an increase in the probability that a settlement occurs? The answer is no. The flaw in this line of reasoning is that it implicitly assumes that the bargaining strategies are unaffected by the changes in compatibility factor. This 
is not the case, however, since it is easy to show that changes in the compatibility factor have a drastic effect on the equilibrium behavior of the parties: other things equal, when $\delta$ increases, both the buyer and the seller become more aggressive, the buyer moving closer to his reservation value, the seller asking an higher price.

Lemma 2. Under the automated negotiation bargaining rule, considering the case in which there is a positive compatibility factor, the equilibrium offer strategies are

$$
p_{b}\left(v_{b}\right)=b(\delta) v_{b} \text { and } p_{s}\left(v_{s}\right)=s(\delta) v_{s}+c(\delta)
$$

where $b(\delta)=2(1+\delta) /\left(\delta^{2}+4 \delta+2\right), s(\delta)=2(1+\delta) /(2+\delta)^{2}$ and

$$
c(\delta)=4(1+\delta)^{3} /(2+\delta)^{2}\left(\delta^{2}+4 \delta+2\right) .
$$

Proof. See appendix 4.2.

Remark that $b(0)=1$ and $s(0)=c(0)=1 / 2$, in accordance with the results stated in Lemma 1. Following these expressions, a straightforward comparative statics analysis can confirm that, as $\delta$ increases, the slope of each offer strategy decreases causing the players' bargaining positions to become more aggressive:

$$
b^{\prime}(\delta)=\frac{-2\left(\delta^{2}+2 \delta+2\right)}{\left(\delta^{2}+4 \delta+2\right)^{2}}<0 \text { and } s^{\prime}(\delta)=\frac{-2 \delta}{(2+\delta)^{3}}<0, \text { since } \delta>0
$$

The players' offer strategies are sensitive to changes in the compatibility factor in a natural way: with an increasing compatibility factor, the marginal increment in profit associated with a slighty more agressive offer (i.e. a higher seller offer or a lower buyer offer) becomes weighted more heavily than the possible loss, if as a result of the change, an agreement is precluded. This fact leads the players to move away from their true valuations. Therefore, what is the effect of this bargaining behavior on the probability that an agreement occurs (i.e. on the size of the settlement zone) in the automated negotiation process? In fact, the compatibility factor has two opposite implications:

First, by providing the parties an additional possibility to reach an agreement (i.e. when $\left.p_{b}(1+\delta) \geq p_{s}>p_{b}\right)$, the compatibility factor increases the settlement zone for given bargaining strategies. Manipulating the equilibrium offer strategies in Lemma 2 shows that such an "assisted settlement" occurs in equilibrium if and only if:

$$
\left[\frac{\delta^{2}+4 \delta+2}{(2+\delta)^{2}}\right] v_{s}+\frac{2(1+\delta)^{2}}{(2+\delta)^{2}}>v_{b} \geq\left[\frac{\delta^{2}+4 \delta+2}{(1+\delta)(2+\delta)^{2}}\right] v_{s}+\frac{2(1+\delta)}{(2+\delta)^{2}}
$$

A straightforward comparative statics analysis can confirm that $\delta$ has a positive (resp. negative) impact on the left-hand side (resp. right-hand side) of (8), which increases the assisted settlement zone.

Furthermore, as explained above, the compatibility factor leads the players to become more aggressive and, therefore, discourages them to converge on their own. Given that 
such a "free settlement" is reached if and only if $p_{b} \geq p_{s}$, manipulating the equilibrium offer strategies in Lemma 2 shows that such an agreement occurs in equilibrium if and only if:

$$
v_{b} \geq\left[\frac{\delta^{2}+4 \delta+2}{(2+\delta)^{2}}\right] v_{s}+\frac{2(1+\delta)^{2}}{(2+\delta)^{2}}
$$

It is rather simple to confirm that $\delta$ has a positive impact on the right-hand side of (9), which decreases the free settlement zone.

The global effect of the compatibility factor on the probability that a settlement occurs is not significant, except for extreme values of $\delta$ which do not exist in the real automated negotiation procedures:

\begin{tabular}{|c|c|c|c|}
\cline { 2 - 4 } \multicolumn{1}{c|}{} & $\begin{array}{c}\text { Assisted settlement zone: } \\
{\left[p_{b}(1+\delta) \geq p_{s}>p_{b}\right]}\end{array}$ & $\begin{array}{c}\text { Free settlement zone: } \\
{\left[p_{b} \geq p_{s}\right]}\end{array}$ & $\begin{array}{c}\text { Settlement zone: } \\
{\left[p_{b}(1+\delta) \geq p_{s}\right]}\end{array}$ \\
\hline $\begin{array}{c}\text { Effect of an increase } \\
\text { in } \delta:[\Delta \delta>0]\end{array}$ & + & & \\
& & - & \\
\hline
\end{tabular}

In order to illustrate the very low sensitivity of the settlement zone to changes in the compatibility factor, we consider only two extreme values of $\delta$, that is $\delta=\{0,0.5\}$. The hatched area characterizes the efficiency gain due to the increase in the compatibility factor.

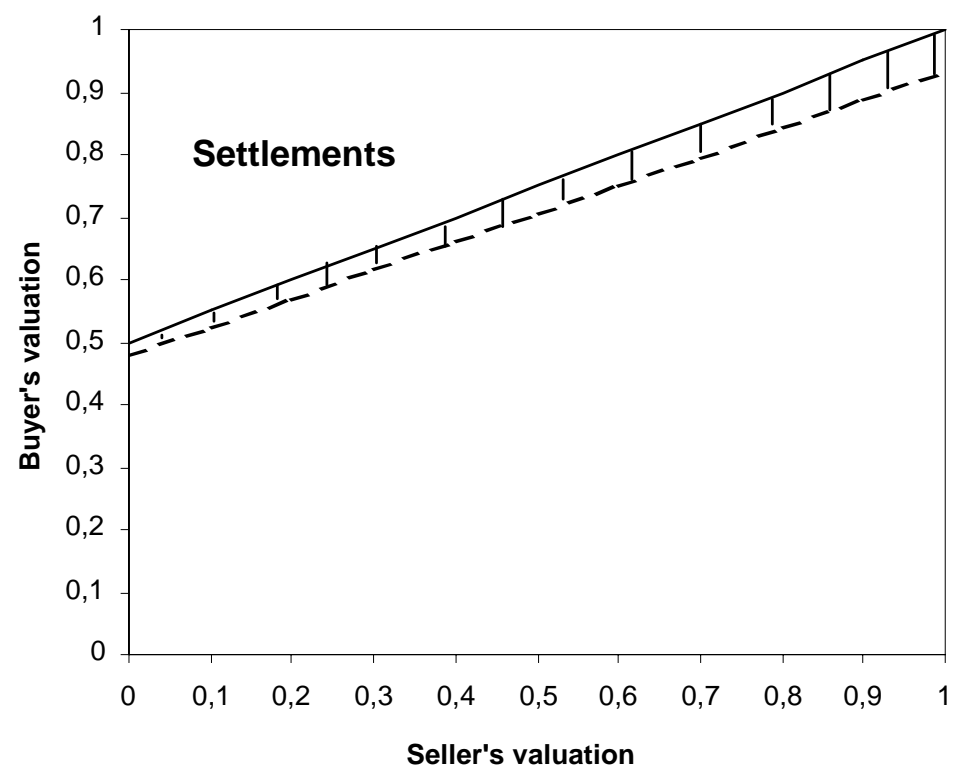

Figure 2 - Settlement zones when $\delta=\{0,0.5\}$ 
where the solid (resp. dash) straightline corresponds to the equation $v_{b}=\left[\frac{\delta^{2}+4 \delta+2}{(1+\delta)(2+\delta)^{2}}\right] v_{s}+$ $\frac{2(1+\delta)}{(2+\delta)^{2}}$ with $\delta=0$ (resp. $\left.\delta=0.5\right)$.

The result illustrated in this figure is stated precisely in the following Proposition.

Proposition 2. Under the automated negotiation bargaining rule, the compatibility factor does not improve significantly the efficiency of the settlement zone.

This result indicates that, as the compatibility factor increases, the gain in efficiency due to the increase in the assisted settlement zone is approximatively offset by the efficiency loss due to the decrease in the free settlement zone, causing the settlement zone to be slighlty affected by changes in $\delta$. The intuition underlying this analysis is the following: the compatibility factor decreases the pressure on the parties to take realistic bargaining positions and to move closer their true values because each party seems to believe that he is "protected" of a disagreement by the existence of $\delta$. However, this protection induces also a perverse effect by discouraging the parties to converge on their own: although each player increases the probability that an agreement occurs by compromising his offer, this gain in probability is more than offset by the loss in potential payoff it suffers when $\delta$ increases. The parties have more reluctance to concede during negotiations because the threat that a disagreement occurs is less credible for high values of $\delta$. Therefore, at the same time as the assisted settlement zone increases, the compatibility factor has a drastic and negative effect on the probability that a free settlement occurs. These elements make the automated negotiation mechanism corresponds with the prisonner's dilemma: each party has a strong individual incentive to exploit strategically the compatibility factor and take agressive bargaining positions which, in turn, leads to a collective inefficient result. As a result, the well-known criticism about arbitration, mentioned in the introduction, is still relevant regarding the automated negotiation procedure. The automated negotiation agreements tend to be of low quality in the sense that they lie outside the range of free negotiated settlements. The results indicate that the parties have correctly perceived the strategic implications of the compatibility factor and have incentives to adopt aggressive bargaining positions. Given that the compatibility factor increases the assisted settlement zone and decreases the free settlement zone, it appears that the players' convergence is only driven by this parameter.

However, additional insight into the nature of the bargaining equilibrium can be gained by relaxing the assumption that the parties are risk neutral. The dependence of the players' offer strategies and the settlement zone on risk preferences of the parties is investigated in the following section. 


\subsection{Players Risk Aversion}

We consider that the players' utility functions display constant relative risk aversion,

$$
u(y)=y^{\alpha}
$$

, where $\alpha \in[0,1]$. As a simple illustration, let the parties be equally risk-averse in the following sense: in the limit as $\alpha$ approaches 0 (resp. 1), the players become infinitely risk averse (resp. risk neutral). In order to keep the analysis tractable and isolate the effect of risk aversion on the players' strategies, we consider only the case where there is no compatibility factor (i.e. $\delta=0$ ), the results staying relevant for positive values of $\delta$. Following straightforward modifications of equations (5) and (6), it is easy to check that the payoffs to both the buyer and the seller are:

$$
\begin{aligned}
& u_{b}\left(p_{s}, p_{b} ; v_{s}, v_{b}\right)= \begin{cases}\left(v_{b}-p_{s}\right)^{\alpha} & \text { if } p_{b} \geq p_{s} \\
0 & \text { if } p_{b}<p_{s}\end{cases} \\
& u_{s}\left(p_{s}, p_{b} ; v_{s}, v_{b}\right)= \begin{cases}\left(p_{s}-v_{s}\right)^{\alpha} & \text { if } p_{b} \geq p_{s} \\
0 & \text { if } p_{b}<p_{s}\end{cases}
\end{aligned}
$$

Let us consider the effect on the bargaining strategies as the players become increasingly risk averse: as $\alpha$ decreases, the slope of each offer strategy increases. The result is lower seller offers and higher buyer offers.

Lemma 3. Under the automated negotiation bargaining rule, considering the case in which there is no compatibility factor, the equilibrium offer strategies are

$$
p_{b}\left(v_{b}\right)=b(\alpha) v_{b}+d(\alpha) \text { and } p_{s}\left(v_{s}\right)=s(\alpha) v_{s}+c(\alpha)
$$

where $b(\alpha)=2 /(1+\alpha), d(\alpha)=2 \alpha(\alpha-1) /(1+3 \alpha)(1+\alpha)$,

$s(\alpha)=1 /(1+\delta)$, and $c(\alpha)=2 \alpha /(1+3 \alpha)$.

Proof. See appendix 4.3.

Remark that $b(1)=1, d(1)=0$, and $s(1)=c(1)=1 / 2$, in accordance with the results stated in Lemma 1. Furthermore, a straightforward calculation can confirm that, as $\alpha$ decreases, the slope of each offer strategy increases causing the players' bargaining positions to be less aggressive (and the intercept to fall):

$$
b^{\prime}(\alpha)=\frac{-2}{(1+\alpha)^{2}}<0 \text { and } s^{\prime}(\delta)=\frac{-1}{(1+\alpha)^{2}}<0, \text { since } \alpha \geq 0
$$

The intuition behind this result is the following. With risk aversion, the marginal increment in profit associated with a slighty more agressive offer (i.e. a higher seller offer or 
a lower buyer offer) is weighted less heavily than the possible loss. Therefore, the risk averse parties take more reasonable bargaining positions in order to reduce the disutility of a bad outcome if a disagreement occurs. In the case of different degrees of risk aversion, one could show that, other things equal, an increase in the risk aversion of the seller (resp. buyer) implies lower (resp. higher) offers by both parties in equilibrium. Indeed, the opponent's best response to more truthful offers by the player who has become more risk averse is to make more aggressive offers himself.

Not surprisingly, the probability that a settlement occurs in the automated negotiation procedure is sensitive to changes in the level of players risk aversion in the following way: as the players become more risk averse (i.e. $\alpha$ decreases), the settlement zone increases, causing the probability that an agreement occurs to be higher. Given that an agreement is reached if and only if $p_{b} \geq p_{s}$, manipulating the equilibrium offer strategies in Lemma 3 shows that an agreement occurs if and only if:

$$
v_{b} \geq \frac{1}{2} v_{s}+\frac{2 \alpha}{1+3 \alpha}
$$

Following a comparative statics analysis, it is rather simple to check that $\alpha$ has a positive impact on the right-hand side of (12). To illustrate this result, see Figure 3 in which the two extreme values of $\alpha$ are considered (i.e. $\alpha=\{0,1\})$ and the efficiency gain due to the players' risk aversion is characterized by the hatched area.

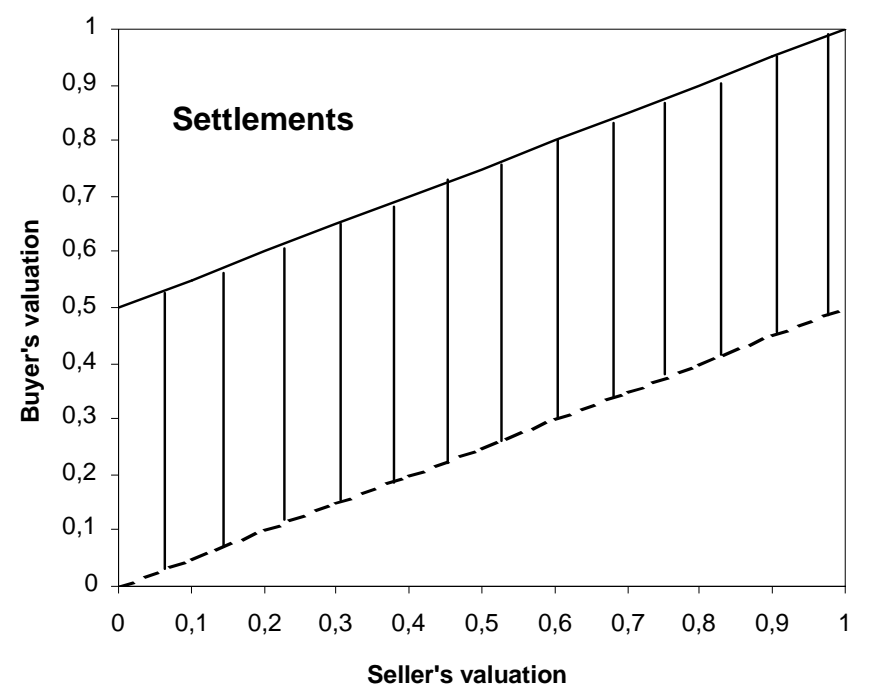

Figure 3 - Settlement zones when $\alpha=\{0,1\}$

where the solid (resp. dash) straightline corresponds to the equation $v_{b}=\frac{1}{2} v_{s}+\frac{2 \alpha}{1+3 \alpha}$ with $\alpha=1$ (resp. $\alpha=0$ ).

The result illustrated in this figure is stated in the following Proposition. 
Proposition 3. Under the automated negotiation bargaining rule, considering the case where there is no compatibility factor, the parties' risk aversion improves significantly the efficiency of the settlement zone.

The intuition underlying this result is the following. The parties' risk aversion is effective in promoting settlements to the extent that it imposes costs on the bargainers in the event they fail to reach an agreement. The ability of the procedure to generate efficiency and induce the parties to reach a settlement is only due to the costs imposed on bargainers if a disagreement occurs, these costs resulting from the combination of risk aversion by the parties and their uncertainty regarding the opponent's valuation.

\section{Concluding Remarks}

In this study a model of the use of automated negotiation procedure and the outcomes of negotiated settlements was developed. The central idea is that the automated negotiation mechanism in combination with the behavioral processes of decision making under uncertainty determine the environment within which the parties negotiate, and consequently, strongly affects the bargaining behavior and the terms of negotiated agreements. We argue that with this relatively simple and natural structure we have been able to demonstrate the following facts: first of all, under the automated negotiation mechanism, the disputants are motivated to posture and make preposterous offers, leading the occurence of a free settlement to be less likely (and the occurence of an assisted settlement to be more likely). The upshot is that the more compromising party, while enhancing its chances of reaching an agreement, does so at the expense of lowering its expected payoff when the parties choose their equilibrium strategies. This result is consistent with the predictions of the arbitration models in the sense that the agreements are driven by the dispute resolution mechanism and lie outside the range of potential negotiated settlements. In fact, the computer software seems to become a neutral third party who drives the players' strategies. Second, for the reasons described above, going to the automated negotiation procedure does not significantly increase the range of possible settlements, which suggests that this dispute resolution mechanism is not a relevant source of efficiency. The ability of the procedure to generate efficiency and induce the parties to reach a settlement is only due to the costs imposed on bargainers if a disagreement occurs. The parties' uncertainty regarding the opponent's valuation alters fundamentally the offer strategies by encouraging concessionary behavior by risk-averse bargainers.

These results have important policy implications for the evaluation and design of automated negotiation systems. Indeed, to the extent that the settlement zone is a convenient measure of the ability of the automated negotiation procedure to promote settlements, this suggests that maintaining such a design is not a good way for increasing the likelihood of a settlement. This conclusion can be of a main importance for several business-to-consumer 
and business-to-business companies (e.g. auction sites, insurance companies) which provide automated negotiation services to resolve disputes between consumers. However, we have only just scratched the surface of the various matters that impige on this issue. Much more work remains to be done in order to develop the automated negotiation procedures. For example, the automated negotiation sytems are limited since they can be employed only when there is a single sticking point and the sticking point involves money or something else that is quantifiable. It could be interesting to develop negotiation softwares intended for use in disputes that are single-issue or multi-issue, two-party or multi-party, composed of quantitative or qualitative issues. 


\section{Appendix}

\subsection{Proof of Lemma 1}

Consider first the buyer's optimal strategy choice. Recall that we consider a Bayesian Nash equilibrium of game between the buyer and the seller, hence when the buyer chooses his offer price he takes the strategy of the seller as given.

The buyer's payoff when we substitute $p_{s}\left(v_{s}\right)$ in $(5)$ is then:

$$
u_{b}\left(p_{s}, p_{b} ; v_{s}, v_{b}\right)= \begin{cases}v_{b}-p_{s}\left(v_{s}\right) & \text { if } p_{b} \geq p_{s}\left(v_{s}\right) \\ 0 & \text { if } p_{b}<p_{s}\left(v_{s}\right)\end{cases}
$$

In other words

$$
u_{b}\left(p_{s}, p_{b} ; v_{s}, v_{b}\right)= \begin{cases}v_{b}-p_{s}\left(v_{s}\right) & \text { if } v_{s} \leq p_{s}^{-1}\left(p_{b}\right) \\ 0 & \text { if } v_{s}>p_{s}^{-1}\left(p_{b}\right)\end{cases}
$$

Using (13) we can rewrite problem (3) as

$$
\max _{p_{b}} \int_{v_{s}=0}^{p_{s}^{-1}\left(p_{b}\right)}\left[v_{b}-p_{s}\left(v_{s}\right)\right] d v_{s}
$$

The first order condition of problem (14) is

$$
\left[v_{b}-p_{b}\right] \frac{d p_{s}^{-1}\left(p_{b}\right)}{d p_{b}}=0
$$

since $p_{b}=p_{s}\left(p_{s}^{-1}\left(p_{b}\right)\right)$.

Consider now the seller's optimal strategy choice.

The seller's payoff obtained by substituting $p_{b}\left(v_{b}\right)$ in $(6)$ is then:

$$
u_{s}\left(p_{s}, p_{b} ; v_{s}, v_{b}\right)= \begin{cases}p_{s}-v_{s} & \text { if } v_{b} \geq p_{b}^{-1}\left(p_{s}\right) \\ 0 & \text { if } v_{b}<p_{b}^{-1}\left(p_{s}\right)\end{cases}
$$

As done above, using (16) we can rewrite problem (4) as

$$
\max _{p_{s}} \int_{v_{b}=p_{b}^{-1}\left(p_{s}\right)}^{1}\left[p_{s}-v_{s}\right] d v_{b}=\left(p_{s}-v_{s}\right)\left[1-p_{b}^{-1}\left(p_{s}\right)\right]
$$

The first order condition of problem (17) is

$$
\left(v_{s}-p_{s}\right) \frac{d p_{b}^{-1}\left(p_{s}\right)}{d p_{s}}+\left[1-p_{b}^{-1}\left(p_{s}\right)\right]=0
$$


To simplify notation we re-write $p_{b}^{-1}()=.q_{b}($.$) and p_{s}^{-1}()=.q_{s}($.$) . The two differential$ equations (15) and (18) define the optimal strategies for the buyer and the seller. Therefore the Bayesian Nash Equilibrium of this bilateral trade model is characterized by the two differential equations:

$$
\begin{aligned}
{\left[q_{b}\left(p_{b}\right)-p_{b}\right] q_{s}^{\prime}\left(p_{b}\right) } & =0 \\
{\left[q_{s}\left(p_{s}\right)-p_{s}\right] q_{b}^{\prime}\left(p_{s}\right)+\left[1-q_{b}\left(p_{s}\right)\right] } & =0
\end{aligned}
$$

From (19) we obtain:

$$
q_{b}\left(p_{b}\right)=p_{b}
$$

Substituting (21) into (20) we obtain:

$$
q_{s}\left(p_{s}\right)=2 p_{s}-1
$$

Using $v_{b}=q_{b}\left(p_{b}\right)$ and $v_{s}=q_{s}\left(p_{s}\right),(21)$ and (22) we conclude that the buyer's and seller's equilibrium strategies are:

$$
p_{b}\left(v_{b}\right)=v_{b} \text { and } p_{s}\left(v_{s}\right)=\frac{1}{2} v_{s}+\frac{1}{2}
$$

Notice that the players' equilibrium strategies are linear:

$$
\begin{aligned}
& p_{b}\left(v_{b}\right)=a_{b}+c_{b} v_{b} \text { with } a_{b}=0 \text { and } c_{b}=1 \\
& p_{s}\left(v_{s}\right)=a_{s}+c_{s} v_{s} \text { with } a_{s}=\frac{1}{2} \text { and } c_{s}=\frac{1}{2}
\end{aligned}
$$

\subsection{Proof of Lemma 2}

In order to keep the analysis tractable, we now derive a linear Bayesian Nash equilibrium of the automated negotiation mechanism. We are not restricting the players' strategy spaces to include only linear strategies. Rather, we allow the players to choose arbitrary strategies but ask whether there is an equilibrium that is linear (Gibbons 1992).

Therefore, suppose the seller's strategy is $p_{s}\left(v_{s}\right)=a_{s}+c_{s} v_{s}$ and the buyer's one is $p_{b}\left(v_{b}\right)=$ $a_{b}+c_{b} v_{b}$. Then $p_{s}$ is uniformly distributed on $\left[a_{s}, a_{s}+c_{s}\right]$ and $p_{b}$ is uniformly distributed on $\left[a_{b}, a_{b}+c_{b}\right]$.

If there is a positive compatibility factor (i.e. $\delta>0$ ), then (3) and (4) become

$$
\begin{aligned}
& \max _{p_{b}}\left(v_{b}-\frac{a_{s}+p_{b}}{2}\right) \frac{p_{b}-a_{s}}{c_{s}}+\left[v_{b}-\frac{p_{b}(4+\delta)}{4}\right] \frac{\delta p_{b}}{c_{s}} \\
& \max _{p_{s}}\left(p_{s}-v_{s}\right) \frac{a_{b}+c_{b}-p_{s}}{c_{b}}+\left[\frac{p_{s}(4+3 \delta)}{4(1+\delta)}-v_{s}\right] \frac{\delta p_{s}}{c_{b}(1+\delta)}
\end{aligned}
$$

The first-order conditions for which yield

$$
\begin{aligned}
& p_{b}=\frac{2(1+\delta)}{\delta^{2}+4 \delta+2} v_{b} \\
& p_{s}=\frac{2(1+\delta)}{(2+\delta)^{2}} v_{s}+\frac{2(1+\delta)^{2}}{(2+\delta)^{2}}\left(a_{b}+c_{b}\right)
\end{aligned}
$$


Given the linear strategies $p_{b}\left(v_{b}\right)=a_{b}+c_{b} v_{b}$ and $p_{s}\left(v_{s}\right)=a_{s}+c_{s} v_{s}$, by manipulating (23) and (24), the linear equilibrium strategies are

$$
\begin{aligned}
& p_{b}\left(v_{b}\right)=\frac{2(1+\delta)}{\delta^{2}+4 \delta+2} v_{b} \\
& p_{s}\left(v_{s}\right)=\frac{2(1+\delta)}{(2+\delta)^{2}} v_{s}+\frac{4(1+\delta)^{3}}{(2+\delta)^{2}\left(\delta^{2}+4 \delta+2\right)}
\end{aligned}
$$

\subsection{Proof of Lemma 3}

If the players are risk averse (i.e. $\alpha>0$ ), then (3) and (4) become

$$
\begin{aligned}
& \max _{p_{b}}\left(v_{b}-\frac{a_{s}+p_{b}}{2}\right)^{\alpha}\left(\frac{p_{b}-a_{s}}{c_{s}}\right) \\
& \max _{p_{s}}\left(p_{s}-v_{s}\right)^{\alpha}\left(\frac{a_{b}+c_{b}-p_{s}}{c_{b}}\right)
\end{aligned}
$$

The first-order conditions for which yield

$$
\begin{aligned}
& p_{b}=\frac{2}{1+\alpha} v_{b}+\frac{\alpha-1}{1+\alpha} a_{s} \\
& p_{s}=\frac{1}{1+\alpha} v_{s}+\frac{\alpha}{1+\alpha}\left(a_{b}+c_{b}\right)
\end{aligned}
$$

Given the linear strategies $p_{b}\left(v_{b}\right)=a_{b}+c_{b} v_{b}$ and $p_{s}\left(v_{s}\right)=a_{s}+c_{s} v_{s}$, by manipulating (25) and (26), the linear equilibrium strategies are

$$
\begin{aligned}
& p_{b}\left(v_{b}\right)=\frac{2}{1+\alpha} v_{b}+\frac{2 \alpha(\alpha-1)}{(1+3 \alpha)(1+\alpha)} \\
& p_{s}\left(v_{s}\right)=\frac{1}{1+\alpha} v_{s}+\frac{2 \alpha}{1+3 \alpha}
\end{aligned}
$$




\section{References}

[1] Chatterjee, K., and W. Samuelson (1983), "Bargaining Under Incomplete Information", Operations Research, 31, 835-851.

[2] Coase, R. (1937), "The Nature of the Firm", Economica, 4, 386-405.

[3] Crawford, V.P. (1979), "On Compulsory Arbitration Schemes", Journal of Political Economy, 87, 131-160.

[4] Deffains, B., and P. Fenoglio (2001), "Economie et ordre juridique de l'espace virtuel", Revue Economique, 52, 331-348.

[5] Farber, H.S. (1980), "An analysis of Final-Offer Arbitration", Journal of Conflict Resolution, 24, 683-705.

[6] Farber, H.S. (1981), "Splitting-the-Difference in Interest Arbitration", Industrial and Labor Relations Review, 35, 70-77.

[7] Farber, H.S., and H.C. Katz (1979), "Interest Arbitration, Outcomes, and the Incentives to Bargain", Industrial and Labor Relations Review, 33, 55-63.

[8] Fudenberg, D., and J. Tirole (1991), Game Theory, MIT Press.

[9] Gibbons, R. (1992), Game Theory for Applied Economists, Princeton University Press.

[10] Keser, C. (2002), "Trust and Reputation Building in E-Commerce", working paper, CIRANO.

[11] Muthoo, A. (1999), Bargaining Theory with Applications, Cambridge University Press.

[12] Myerson, R.B., and M. Satterthwaite (1983), "Efficient Mechanisms for Bilateral Trading", Journal of Economic Theory, 28, 265-281.

[13] Rule, C. (2002), Online Dispute Resolution For Business, Jossey-Bass Press. 